\title{
The role of innate immune signals in immunity to Brucella abortus
}

\author{
Marco Túlio R. Gomes, Priscila C. Campos, Leonardo A. de Almeida, Fernanda S. Oliveira, \\ Miriam Maria S. Costa, Fernanda M. Marim, Guilherme S. M. Pereira and Sergio C. Oliveira*
}

Department of Biochemistry and Immunology, Institute of Biological Sciences, Federal University of Minas Gerais, Belo Horizonte, MG, Brazil

\author{
Edited by: \\ Nelson Gekara, Umea University, \\ Sweden \\ Reviewed by: \\ Bastian Opitz, Charite University \\ Medicine Berlin, Germany \\ Yongqun "Oliver" He, University of \\ Michigan School of Medicine, USA \\ *Correspondence: \\ Sergio C. Oliveira, Department of \\ Biochemistry and Immunology, \\ Institute of Biological Sciences, \\ Federal University of Minas Gerais, \\ Av., Antonio Carlos 6627, Pampulha, \\ Belo Horizonte, MG, Brazil. \\ e-mail:scozeus@icb.ufmg.br
}

Innate immunity serves as the first line of defense against infectious agents such as intracellular bacteria. The innate immune platform includes Toll-like receptors (TLRs), retinoid acid-inducible gene-l-like receptors and other cytosolic nucleic acid sensors, nucleotide-binding and oligomerization domain-like receptors, adaptors, kinases and other signaling molecules that are required to elicit effective responses against different pathogens. Our research group has been using the Gram-negative bacteria Brucella abortus as a model of pathogen. We have demonstrated that $B$. abortus triggers MAPK and NF-kB signaling pathways in macrophages in a MyD88 and IRAK-4-dependent manner. Furthermore, we claimed that so far TLR9 is the most important single TLR during Brucella infection. The identification of host receptors that recognize pathogen-derived nucleic acids has revealed an essential role for nucleic acid sensing in the triggering of immunity to intracellular pathogens. Besides TLRs, herein we describe recent advances in NOD1, NOD2, and type I IFN receptors in innate immune pathways during $B$. abortus infection.

Keywords: Brucella abortus, innate immunity, type I interferon, TLR signaling, NLR

\section{INTRODUCTION}

The immune system traditionally has been divided into innate and adaptive that act in an integrated manner to elicit an effective host resistance. The adaptive immune system is slower to develop a response against pathogens when compared to the innate immunity. It responds to specific antigens and generates immunological memory. On the contrary, the innate immune response is rapid and functions as the first line of defense against pathogens. Besides the physical barriers at the surface of the body and the soluble factors, such as complement proteins, it consists mainly of diverse cellular components including macrophages, dendritic cells (DCs), granulocytes (basophils, eosinophils, and neutrophils), and natural killer cells (Dranoff, 2004).

Pathogens regularly display a molecular signature known as pathogens-associated molecular patterns (PAMPs). The most common PAMPs are lipopolysaccharide (LPS), peptidoglycan (PGN), bacterial lipoproteins, flagellin, and nucleic acids derived from viruses, bacteria, fungi, and protozoa. The host innate immune system can interact with these PAMPs using a broad range of germ-line encoded pattern-recognition receptors (PRRs). PRRs comprise the membrane-bound Toll-like receptors (TLRs), which are located either at the cytoplasmic membrane or at the membranes encompassing endosomal vesicles, and sense molecules in the extracellular compartments and endosomal lumen, respectively (Kumar et al., 2011). However, other PRRs can interact with cytosolic stimuli and play an additional role in host-surveillance. The cytosolic RNA-sensing RNA helicases retinoic acid-inducible gene I (RIG-I) and melanoma differentiation-associated gene 5 (MDA5) (Yoneyama et al., 2005); the cytosolic DNA sensors, absent in melanoma 2 (AIM2) and DNA-dependent activator of IRFs (DAI) (Takaoka et al., 2007; Hornung et al., 2009); as well as the nucleotide binding and oligomerization domain (NOD)-like receptors (NLRs) are included in this panoply of intracellular PRRs that recognizes PAMPs and host-derived danger signals (danger-associated molecular patterns, DAMPs) (Schroder and Tschopp, 2010).

Usually, the innate immune cells drive a response against pathogens by sensing molecular stimuli that activate multiple cascades culminating in the expression of an array of genes. Typically, an intact microbial pathogen displays a set of PAMPs that activate multiple PRRs in host cells. This is considered the first step in the activation of multiple intracellular signaling pathways. Hence, signal transduction initiated after the interaction between a PAMP with a specific PRR generally results in the activation of transcription factors. The translocation of activated transcription factors to the cell nucleus ultimately leads to the expression of inflammatory cytokines, type I interferon (IFN), chemokines and other compounds responsible to generate an efficient response against an infection (Bonizzi and Karin, 2004).

The genus Brucella is composed of facultative intracellular Gram-negative bacteria that cause brucellosis, a systemic infectious zoonotic disease characterized, among others symptoms, by undulant fever in humans. It was first identified by Sir David Bruce in the 1860s in Malta, which became known as Malta fever (Araj, 2010). The species of Brucella are classified according to their preference for specific animal hosts. For instance, the bacterium B. abortus naturally infects and causes abortion in cattle, being responsible for severe economical loss (Pappas, 2010). The contacts with infected cattle as well as the consumption of unpasteurized milk from this source are 
important routes for the transmission of B. abortus to humans (Godfroid et al., 2011).

The strategy of $B$. abortus is to evade the innate immune system and persist in the host long enough to be transmitted. The bacterium contains an unusual lipid A composing the LPS molecule, which is important for evading the host immune system during the early stages of infection (Parent et al., 2007). In addition, when entering the host intracellular space, $B$. abortus displays several strategies to avoid the cellular killing mechanism. One of the main virulent factors involved in such action is the Type IV secretion system (T4SS) which is encoded by the virB operon (de Jong and Tsolis, 2012). After B. abortus is phagocytized, T4SS is induced during phagosomal acidification, leading to the translocation of effector proteins into host cytosol. This process is essential for bacteria subvert lysosome fusion and to create Brucella-containing vacuole (BCV), an organelle permissive for replication that interacts with the endoplasmic reticulum (ER) (Celli et al., 2003).

Another strategy employed by $B$. abortus to survive and replicate within macrophages involves host cell death. The attenuated rough $B$. abortus strain RB51 lacks the O-antigen of LPS while the virulent smooth strain S2308 contains the O-antigen portion. It was shown that although RB51 strain induces caspase2-dependent apoptosis in macrophages, its parental strain 2308 inhibited this programmed cell death mechanism (Chen and He, 2009). Moreover, the apoptosis promoted by rough strains in macrophages was correlated with activation of the NF- $\kappa \mathrm{B}$ pathway and production of inflammatory cytokines such as TNF- $\alpha$ (Chen et al., 2011). Interestingly, both S2308 and RB51 induce caspase-2-dependent apoptosis in DC albeit more cell death is promoted by S2308. Taken together, S2308 infection promotes DC apoptosis reducing DC maturation and S2308 antigens presentation to $\mathrm{T}$ cells. In addition, the virulent Brucella inhibits macrophage cell death avoiding the exposure to the more hostile extracellular environment propitiating the survival and replication inside this cell. In such scenario, the induction of DC cell death and inhibition of macrophage apoptosis might contribute to Brucella pathogenesis ( $\mathrm{Li}$ and $\mathrm{He}, 2012$ ).

Although the stealthy strategy employed by B. abortus attempt to create a propitious environment for its replication, host cells are equipped with molecules that interact direct or indirect with this bacterium in order to control the infection. Herein, we will review the prominent findings that have contributed to our understanding of the molecular mechanisms underlying innate immune cell recognition and response to $B$. abortus infection (Figure 1).

\section{TLR SIGNALING AND ITS ROLE DURING Brucella abortus INFECTION}

The TLR family was originally identified in Drosophila, where it triggers essential developmental and immunological signaling (Hashimoto et al., 1988). These PRRs were later extensively characterized and their role in innate immunity well established. Currently, 12 members of the TLR family have been identified in mammals being 10 TLRs in humans (TLR1-10). TLR11-13, although less characterized, have been identified in mice, while TLR10 is not expressed in these animals (Kumar et al.,
2011). TLRs are type I transmembrane proteins containing three domains: an extracellular domain containing leucine-rich repeats (LRR), which binds PAMPs; a transmembrane domain, spanning the cytoplasmic or endosomal membranes; and an intracellular Toll-Interleukin (IL)-1 receptor (TIR) domain, which interacts with downstream adapter proteins. A common feature of TLRs is to form homo- or heterodimers upon interaction with PAMPs (Kondo et al., 2012).

Based on the cellular localization, TLRs can be divided into two groups. The first group comprises members of TLR family expressed on the cell surface, such as TLR2 which forms heterodimers with TLR1 or TLR6, recognizing bacterial lipopeptides (Kang et al., 2009). Other members that are expressed on cell surface are TLR4 and TLR5, which interacts with bacterial LPS and flagellin, respectively. TLR4 requires the adaptor molecule MD-2 to recognize its ligand. Indeed, MD-2 interacting with TLR4 molecule provides the major LPS binding site, inducing homodimerization of the TLR4-MD-2 complex (Park et al., 2009). Similar to TLR4, upon interaction with its cognate ligand, TLR5 also forms a dimer (Yoon et al., 2012). The second group of TLRs resides in intracellular compartments, with the LRR domains facing organelle lumens and interacting with nucleic acids derived from viral or bacterial pathogens. This group includes TLR3, that recognizes double stranded RNA (dsRNA); TLR7-8, that interacts with single stranded RNA (ssRNA) and TLR9, which binds unmethylated CpG DNA (Chaturvedi and Pierce, 2009; Blasius and Beutler, 2010). Initially, these TLRs are located at ER where they physically interact with UNC93B1. This molecule mediates the translocation of the nucleotide-sensing TLRs from the ER to the endolysosomal compartment, allowing their proper activation by microbial RNA and DNA (Kim et al., 2008).

Activation by PAMPs induces TLRs dimerization which brings the intracellular TIR domains close enough to favor the recruitment of TIR adaptors. This interaction initiates cell signaling leading to transcription factors activation (Zhu and Mohan, 2010; Kawai and Akira, 2011). All TLRs, except TLR3, use the myeloid differentiation factor-88 (MyD88) as adaptor. TLR1, TLR2, TLR4, and TLR6 recruit the TIR domain containing adaptor protein (TIRAP), which acts as a bridge between TLR and MyD88. Activation of TLR3 and TLR4 recruits the TIR domain-containing adapter-inducing IFN- $\beta$ (TRIF), and TLR4 also requires the adaptor TRIF-related adapter molecule (TRAM) (Kenny and O'Neill, 2008). The recruitment of MyD88 after TLR dimerization is followed by the IL-1 receptor-associated kinase (IRAK) family activation. The IRAKs then recruit the ubiquitin ligase TNF receptor associated (TRAF6) which, in turn, activates TGF-beta-associated kinase 1 (TAK1) (Sorrentino et al., 2008). The TAK1 protein phosphorylates and activates IкB kinase complex (IKK) (Fraczek et al., 2008) and mitogen activated protein kinases (MAPKs), resulting in activation of nuclear factor (NF)-кB (Bhoj and Chen, 2009) and AP-1 (Cargnello and Roux, 2011) transcription factors, respectively. Besides the induction of inflammatory cytokines secretion promoted by TLR7 and TLR9 through NF- $\kappa \mathrm{B}$ activation, alternatively these receptors elicit the production of type I IFNs by activating the IFN regulatory factor-7 (IRF-7) (Barber, 2011). Activation of TLR3 involves two distinct pathways initiated by 


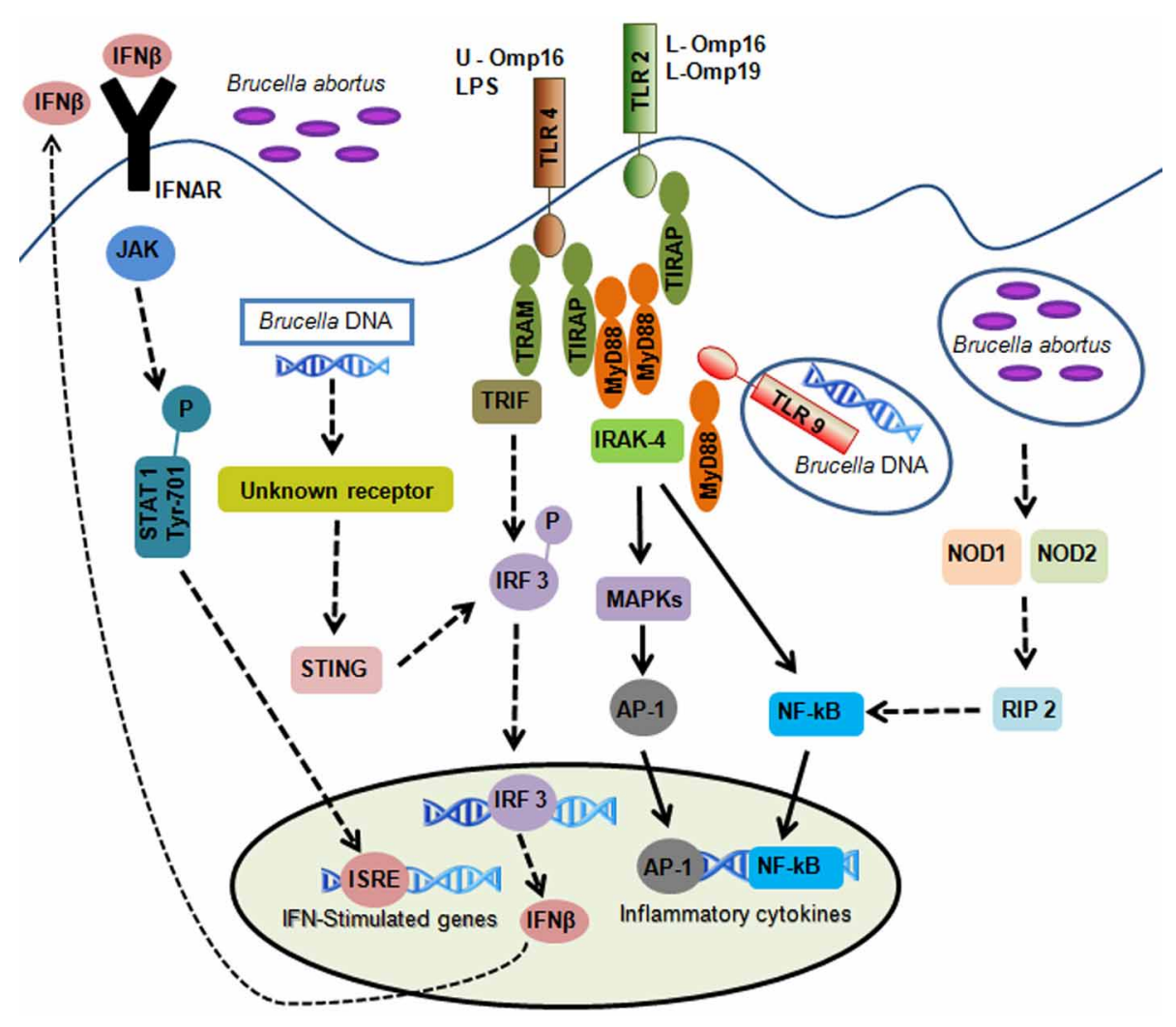

FIGURE 1 | Overview of innate immune signals during $B$. abortus infection. B. abortus-associated molecular patterns are recognized by pattern-recognition receptors. TLR2 is activated by lipidated outer membrane proteins (L-Omp16 and L-Omp19); TLR4 is activated by $B$. abortus LPS and unlipidated outer membrane protein-16 (U-Omp16); and TLR9 is activated by B. abortus DNA. TLR activation leads to intracellular signaling via MyD88 and IRAK-4 resulting in the activation of NF- $\mathrm{KB}$ and MAPKs producing inflammatory cytokines. Cytosolic sensors are also involved in B. abortus DNA recognition. This pathway involves an unknown receptor leading to IFN- $\beta$ production dependent on STING and IRF3 activation. Autocrine signaling through the IFN I receptor (IFNAR) leads to activation of signal transducers JAK and STAT1 which culminates in the transcriptional induction of genes that carry promoters with IFN-stimulated response elements (ISRE) Other cytosolic receptors such as NOD1 and NOD2 play an additional role in recognizing B. abortus. Activation of these receptors by Brucella culminates in NF-kB activation resulting in cytokines synthesis. Solid arrows represent the TLR and non-TLR signaling pathways involving MyD88/IRAK-4 axis important to control B. abortus infection. Discontinuous arrows represent TLR, NOD1, NOD2, and type I IFN receptor signaling that are not necessary for $B$. abortus clearance. the adaptor TRIF. TRIF recruits TRAF6 resulting in activation of the NF- $\kappa \mathrm{B}$ and inflammatory cytokines expression as described above. Alternatively, TRIF binds TANK-binding kinase 1 (TBK-1) activating IRF-3 promotion IFN- $\beta$ expression (Sato et al., 2003). TLR4 is unique as it recruits four distinct adaptors. The MyD88-dependent pathway involves TIRAP leading to an early-phase activation of NF- $\mathrm{B}$ and AP-1. The MyD88independent pathway requires the endocytosis of TLR4, which is transported to intracellular vesicles, where it forms a complex with TRAM and TRIF. TRIF then recruits TRAF6 which, in turn, activates TAK1, initiating the late-phase activation of NF- $\kappa$ B and AP-1. TRIF also initiates the signaling cascade to activate IRF-3 through TRAF3 and TBK-1, leading to type I IFN expression (Kawai and Akira, 2011).

Based on the cell signaling initiated upon TLRs activation, it is evident that the protein MyD88 plays a pivotal role in the innate immune response against several pathogens. In fact, it was shown that MyD88 $8^{-/}$mice are inefficient to control B. abortus infection and the production of inflammatory cytokines by macrophages is completely abrogated (Weiss et al., 2005). The susceptibility of MyD88 $8^{-/-}$mice to B. abortus infection was further correlated to impaired DC maturation and lack of IL-12 synthesis by our group (Macedo et al., 2008). Moreover, DC activation during infection stimulates T cells to produce IFN- $\gamma$, which plays an essential role controlling $B$. abortus infection (Brandão et al., 2012). IRAK-4, another central protein mediating cell signaling upon TLR activation, was correlated with efficient clearance of $B$. abortus in mice, but not at later phases of infection. Similar to MyD88 $-/-$, macrophages and DC derived from IRAK $4^{-/-}$mice are unable to produce inflammatory cytokines in response to $B$. abortus (Oliveira et al., 2011). The central role attributed to MyD88 and IRAK-4 proteins might suggest the participation of TLRs during the control of B. abortus infection. Initially, it was shown that TLR2 plays no role in controlling B. abortus infection in mice. Regarding TLR4, there are some controversies in the field. The production of TNF- $\alpha$ by macrophages derived from TLR2 ${ }^{-/-}$and TLR $4^{-/-}$mice is reduced in $B$. abortus infection. Furthermore, it was shown 
that the $B$. abortus noncanonical LPS does not display a potent immunostimulatory activity (Weiss et al., 2005). Additionally, it was described a TLR4-dependent production of inflammatory cytokines induced by the unlipidated outer membrane protein (OMP) 16 (U-OMP16) derived from B. abortus (Pasquevich et al., 2010). In addition, murine peritoneal macrophages produce TNF- $\alpha$ and IL- 6 through TLR2 activation upon infection with B. abortus or when stimulated with its lipoprotein L-Omp-19 (Delpino et al., 2012). This result confirms the idea that lipoproteins instead LPS are the main mediators of the inflammatory response elicited by B. abortus (Giambartolomei et al., 2004). Thus, TLR2 recognizes $B$. abortus components inducing inflammatory cytokines production. However, this receptor plays no role in mice resistance to $B$. abortus infection in vivo. Moreover, TLR9 was correlated with proper $B$. abortus infection control in mice, at least in early stages of infection (at two weeks). Additionally, the production of inflammatory cytokines by DC and macrophages derived from TLR9 $^{-/-}$mice are partially reduced upon stimulation with heat-killed B. abortus ( $\mathrm{HKBa})$ (Macedo et al., 2008).

The production of immune mediators upon TLR activation depends on intracellular signaling of MAPKs, which include the extracellular signal-regulated kinases 1 and 2 (ERK1/2), c-Jun amino-terminal kinases (JNK) and p38 (Cargnello and Roux, 2011). Previously, it was shown that B. abortus rough mutant RB51 and smooth wild type S2308 strain induce phosphorylation of ERK1/2 and p38. However, the activation of these MAPKs is more prominent when the rough strain was used as stimulus (Jiménez De Bagüés et al., 2005). Moreover, our group showed that ERK1/2 and p38 as well as p65 NF$\kappa \mathrm{B}$ phosphorylation is profoundly impaired in IRAK-4-/and $\mathrm{MyD} 88^{-/-}$macrophages activated by B. abortus (Oliveira et al., 2011). Clearly, the requirement of MyD88 and IRAK-4 in MAPKs activation argues to the participation of TLRs in cell signaling upon $B$. abortus infection. Indeed, it was shown that $\mathrm{HKBa}$ triggers ERK1/2 and p38 phosphorylation through activation of TLR2 in DCs. In that case, p38 but not ERK1/2 activation is correlated with HKBa phagocytosis and IL-12 production (Zhang et al., 2012). Taken together, these findings suggest that $B$. abortus might activate several innate receptors culminating in cell signaling activation and cytokine production.

\section{NOD LIKE-RECEPTORS (NLRs): NOD1, NOD2, AND INFLAMMASOMES}

The NLRs are intracellular molecules that play a critical role in the innate immune system providing surveillance by recognizing structures carried by microbial components at the cytosol (Shaw et al., 2008). NLRs are expressed in immune and non-immune cells such as epithelial and mesothelial cells. There are 23 NLR family members in humans and at least 34 genes in mice (Franchi et al., 2009b). NLRs contain a nucleotide-binding domain (NBD) and a LRR domain. The NBD binds nucleotides inducing conformational changes that are essential to NLRs functions. The LRR domain is required to sense different microbial and endogenous damage stimuli (PAMPs and DAMPs) (Elinav et al., 2011; Franchi et al.,
2012). The NLRs display other additional domains that include an amino (N)-terminal caspase recruitment domain (CARD), pyrin domain and acidic transactivating domain or baculovirus inhibitor repeat that mediates downstream protein-protein interaction (Franchi et al., 2012).

The first identified NLRs, NOD1, and NOD2, recognize cell wall fragments from Gram-negative and Gram-positive bacteria. NOD1 senses a specific PGN fragment containing diaminopimelic acid (DAP) that is produced by most Gramnegative and certain Gram-positive bacteria (Chamaillard et al., 2003); while NOD2 is activated by muramyl dipeptide (MDP), which is a conserved structure in practically all types of PGN (Pauleau and Murray, 2003). Following stimulation by their specific bacterial molecules such as DAP or MDP, NOD1, and NOD2 associate with an adaptor molecule, RIP2, through CARD-CARD interaction, which leads to activation of NF- $\kappa \mathrm{B}$ and MAPKs promoting induction of numerous genes involved in inflammatory process (Kobayashi et al., 2002; Abbott et al., 2004).

Recent studies described the importance of NOD1 and/or NOD2 signaling in host defense against microbial pathogens such as Salmonella enterica (Keestra et al., 2011), Helicobacter pylori (Viala et al., 2004), Listeria monocytogenes (Kobayashi et al., 2005), Staphylococcus aureus (Hruz et al., 2009), and Legionella pneumophila (Frutuoso et al., 2010). Although macrophages derived from NOD2-deficient mice were impaired in the production of inflammatory cytokines upon Mycobacterium tuberculosis infection, this receptor plays no role controlling the replication of M. tuberculosis infection in vivo (Gandotra et al., 2007).

Inflammasomes are multiprotein complexes that activate caspase-1 which leads to maturation of the inflammatory cytokines IL-1 $\beta$ and IL-18 and the induction of pyroptosis (Franchi et al., 2009a; Miao et al., 2011). The activation and release of IL- $1 \beta$ and IL-18 requires two signals: the first signal involves the production of inactive precursors (pro-IL-1 $\beta$ and pro-IL-18) and the second signal results in the assembly of the inflammasome and activation of caspase-1 (which might require the adaptor ASC). The activation of caspase- 1 is also involved in the induction of pyroptosis, autophagy and pathogen degradation through unidentified mechanisms (Fernandes-Alnemri et al., 2007; Schroder and Tschopp, 2010).

Four major inflammasomes have been identified, three of which belong to NLR family, named after the receptor that regulates their activity: NLR family, pyrin domain-containing $1 \mathrm{~B}$ (NLRP1B); NLR family, pyrin domain-containing 3 (NLRP3); NLR family, CARD-containing 4 (NLRC4); and AIM2, a receptor of the HIN family of protein (Franchi et al., 2012). Each inflammasome is assembled in a stimulus-specific manner to cluster molecules of pro-caspase-1. For instance, the NLRP1 inflammasome is activated by anthrax lethal toxin and there is some evidence that NLRP1 may detect PGN (Boyden and Dietrich, 2006; Faustin et al., 2007). As for NLRP3, this receptor is activated by a broad range of stimuli, including pathogenderived signals (bacterial and viral RNA, pore-forming toxins), environment-derived factors (silica, asbestos, alum), and DAMPs (ROS, ATP, uric acid, hyaluronan, amyloid- $\beta$ ) (Kanneganti et al., 2006; Mariathasan et al., 2006; Petrilli et al., 2007; Halle et al., 2008; Hornung et al., 2008; Allen et al., 2009; 
Martinon et al., 2009; Yamasaki et al., 2009; Eigenbrod et al., 2012). Regarding NLRC4, it senses flagellin or the basal body rod component of the type 3 secretion system found in some bacteria (Miao et al., 2010). The AIM2 inflammasome is a receptor for cytosolic DNA which promotes caspase-1 activation (Hornung et al., 2009; Rathinam et al., 2010). Pyroptosis and production of IL-1 $\beta$ and IL-18 mediated by inflammasomes have been shown to be protective against many infectious agents, including Gram-positive (e.g., Staphylococcus and Listeria) and Gram-negative (e.g., Salmonella, Legionella, and Pseudomonas) bacteria (Mariathasan et al., 2004, 2006; Lamkanfi and Dixit, 2009; Arlehamn and Evans, 2011; Massis and Zamboni, 2011).

Our group was the first to report the role of the NLRs such as NOD1 and NOD2 during $B$. abortus infection in mice. It was observed a reduced production of TNF- $\alpha$ in bone-marrow derived macrophages from $\mathrm{NOD}^{-/-}$, NOD $2^{-/-}$and $\mathrm{RIP} 2^{-/-}$ mice compared to wild-type animals. However, NOD1-, NOD2-, and RIP2-deficient animals showed the same bacterial load in spleens compared to wild-type mice. These results suggest that these molecules may contribute to signal in response to $B$. abortus but they are not essential for host defense against this infection in vivo (Oliveira et al., 2012).

\section{TYPE I INTERFERON SIGNALING AND ITS ROLE DURING Brucella abortus INFECTION}

Classically, exposure of cells to type I IFN induces an antiviral state that prevents productive viral infection. This premise was postulated by Isaacs and Lindenmann about 60 years ago when they demonstrated the cell ability to resist a virus infection. This phenomenon was then attributed to type I IFN cytokine considered the factor responsible to interfere in the viral infection (Isaacs and Lindenmann, 1957). Type I IFN is represented by several partially homologous genes of $I F N-\alpha$ and a single gene of IFN- $\beta$ and those genes can be expressed by almost any type of cell in response to stimulation of an array of receptors by pathogens (Decker et al., 2005). The most common and prevalent way by which type I IFN is induced is based on innate immune recognition of PAMPs in cell cytosol. The RIG-I and MDA5 are cytoplasmic receptors responsible for triggering type I IFN secretion after foreign dsRNA recognition transmitting intracellular signaling mediated by the mitochondria-localized adaptor molecule IPS-1 (also known as MAVS) and the kinases TBK1 and IKKi to activate IRF3, the main transcription activator of IFN- $\beta$ gene. Cytosolic DNA sensors such as DAI or Z-DNA binding protein 1 are included in other group of innate immune receptors able to induce type I IFN (Takaoka et al., 2007). However, it was demonstrated that DAI is not the only DNA sensor that activates type I IFN production suggesting a redundant pathway of DNA recognition able to induce IFN. Yang and collaborators (2010) showed that a protein called LRRFIP1 was also able to recognize Listeria monocytogenes dsDNA using $\beta$-catenin as transcriptional co-activator of IFN- $\beta$ gene. Chiu and colleagues (2009) suggested another intracellular way to recognize foreign DNA. They proposed a mechanism of dsDNA sensing which depends on the ability of cytosolic B-DNA be transcribed into $5^{\prime}$-ppp RNA by RNA-polymerase III, which then activates type I IFN transcription through RIG-I (Chiu et al., 2009). Besides nucleic acid-sensing immune machinery described, TLRs are also considered innate immune receptors able to induce type I IFN in some cells, as described before. For instance, group B streptococcus has been shown to induce type I IFN by conventional DCs via TLR7, MyD88, and IRF1 (Mancuso et al., 2009).

The IFN- $\beta$ stimulates a classical Janus kinases (Jak1) intracellular pathway through a two subunits receptor called IFN I receptor (IFNAR) (Brierley and Fish, 2002). The subsequent signaling leads to activation of signal transducers (STAT1, STAT2, and IRF9) which culminates in the transcriptional induction of genes that carry promoters with IFN-stimulated response elements (ISRE) such as IRF7. The newly synthesized IRF7 translocated to the nucleus when activated binding to $I F N \alpha / \beta$ promoters. In an autocrine and/or paracrine way, IFN- $\alpha$ or IFN- $\beta$ can act through binding to IFNAR and restart the signaling amplifying the effects of type I IFN (Honda and Taniguchi, 2006). Besides, IFNAR signaling also activates transcriptionally other genes with different action in the cell such as pro-apoptotic genes, chemokines and PKR (dsRNA dependent protein kinase). Regarding that, type I IFN are more than just anti-viral as they play a major role in linking innate to adaptive immunity (Nagarajan et al., 2011).

Besides virus, an increase number of pathogens have been reported to be inducers of type I IFN as bacteria, protozoa, or fungi (Meissner et al., 2005; Monroe et al., 2010; Haque et al., 2011; Sharma et al., 2011; Vivarini Ade et al., 2011). During bacterial infections, type I IFN is often produced, but its effects are conflicting and do not always favoring the immune response of the host against the infection. Type I IFN related to prevent bacterial infection was first demonstrated for pathogens from Chlamydia genus (de La Maza et al., 1985). Type I IFN is able to kill the bacteria and inhibit chronic infection due the cytokine effects in blocking the production of infectious organisms since this effect is reversed by exogenous tryptophan and iron which are essential elements for Chlamydia growth (Ishihara et al., 2005). The limitation of bacterial infection by type I IFN induction was also observed in the case of C. pneumoniae and Legionella pneumophila (Plumlee et al., 2009; Buss et al., 2010). The control of $C$. pneumoniae infection in human endothelial cells was dependent of endogenous IFN- $\beta$ via intracellular signaling dependent of MAVS, IRF3, and IRF7 (Buss et al., 2010). In the case of L. pneumophila, the autocrine type I IFN signaling mediated by IFNAR, in a pathway independent of STAT1, -2, and -3 , is responsible for bacterial control in the host (Plumlee et al., 2009). Also, type I IFN protects mice against Salmonella typhimurium infection due the activation of IFN- $\gamma$ via STAT4 independent of IL-12 (Freudenberg et al., 2002). Other important group of bacteria that activates IFN I after cellular recognition is group A streptococcus in a intracellular pathway that requires MyD88 but is independent of the TLR2, TLR4, and TLR9 (Gratz et al., 2008). On the other hand, there are a variety of bacteria that are recognized by the innate immune system inducing type I IFN but developing a detrimental phenotype to the host. Francisella tularensis and Listeria monocytogenes induce type I IFN during infection and it was demonstrated that the 
signaling mediated by IFNAR is harmful to host since knockout mice for this receptor are more resistant to those infections (Fehr et al., 1997; Auerbuch et al., 2004; Carrero et al., 2004; Stockinger and Decker, 2008; O'Connor et al., 2009; Henry et al., 2010). There are several mechanisms behind type I IFN induction leading to adverse phenotype during bacterial infection. The augmentation of pro-apoptotic stimulus in macrophages and lymphocytes was described in infection with Listeria, Bacillus anthracis, Mycobacteria, and Chlamydia spp and suggested to be related to detrimental phenotype to the host (Carrero et al., 2004; Gold et al., 2004; O'Connell et al., 2004; Decker et al., 2005; Qiu et al., 2008). Even though the pro-apoptotic effects of type I IFN are not fully known, in L. monocytogenes infection, type I IFN facilitates the Listeriolysin O-induced lysis of lymphocytes and macrophages facilitating bacteria spread (Carrero et al., 2004, 2006). Type I IFN also is involved in up-regulation of pro-apoptotic innate sensors, such as TLRs and the inflammasomes (Trinchieri, 2010). For instance, type I IFN induced by Francisella spp infection augments the expression of AIM2 resulting in caspase- 1 activation and in the production of IL- $1 \beta$ and IL-18 as well as inflammasome-mediated cell death in response to cytosolic dsDNA (Choubey et al., 2010; FernandesAlnemri et al., 2010). Also, IFN I induced during F. tularensis and L. monocytogenes infections limits secretion of IL-17 by T cells and limits effective Th1 immune responses to $M$. tuberculosis in part by inducing negative regulator molecules such as suppressor of cytokine signaling proteins (Manca et al., 2005; Henry et al., 2010).

The first observation that Brucella induces type I IFN was made by Huang and colleagues (2005) when IFN- $\alpha$ was detected in serum of wild type mice injected with $\mathrm{HKBa}$ and the level was markedly reduced in the TLR9 ${ }^{-/}$mice serum, demonstrating that $\mathrm{HKBa}$ induces IFN- $\alpha$ in a TLR9-dependent manner. Additionally, it has shown that $B$. abortus is able to induce IFN- $\beta$ in DCs (Salcedo et al., 2008). Our group has revealed recently an interesting role of type I IFN during $B$. abortus infection (de Almeida et al., 2011). The absence of type I IFN signaling enhanced host protection to B. abortus infection since IFNAR ${ }^{-/-}$ showed to be more resistant to infection than wild type mice. Additionally the spleen derived from Brucella-infected IFNAR ${ }^{-/-}$ mice exhibited a drastic reduction in splenic apoptosis compared to wild type controls similar to L. monocytogenes results presented by Carrero et al. (2006). Mice lacking IFNAR were more resistant to $B$. abortus infection and displayed less apoptotic lesions as well as reduced expression of pro-apoptotic gene TRAIL than their wild type counterparts speculating that type I IFN signaling enhances immune cells apoptosis; therefore, causing the increased susceptibility to $B$. abortus. Furthermore, we demonstrated that $B$. abortus DNA is a major bacterial component to induce IFN- $\beta$ in macrophages occurring mostly independent of TLRs. Surprisingly, type I IFN expression by B. abortus or its DNA was dependent on MyD88, a intracellular pathway observed in Streptococcus and Bacillus anthracis infection mediated by an unknown PRR (Glomski et al., 2007; Gratz et al., 2008; de Almeida et al., 2011). On the other hand, we demonstrated that the adaptor molecule TRIF played no role in type I IFN induction or in vivo host control of B. abortus. In addition, we and other groups are intensively searching for cytosolic receptors which are capable of sensing pathogen nucleic acids released from lysed bacteria or from bacterial secretion system during infection (Monroe et al., 2010). Regarding that, we analyzed the potential role of RNA polymerase III in detecting segments of $B$. abortus DNA transcribing them into RNA that induce IFN- $\beta$ possibly through the RIG-I pathway. Using a inhibitor of RNA polymerase III (ML-60218) (Chiu et al., 2009), we suggested that this enzyme plays a key role in sensing bacterial DNA during $B$. abortus infection triggering intracellular activation of type I IFN. Additionally, the type I IFN induction promoted by $B$. abortus DNA was mediated by an ER resident transmembrane protein termed stimulator of IFN genes (STING) (de Almeida et al., 2011). STING was also identified as essential for type I IFN production in response to L. monocytogenes and C. muridarum (Ishikawa and Barber, 2008; Prantner et al., 2010). In addition, type I IFN produced in response to B. abortus or its DNA signals in an autocrine manner leading to the Tyr701 phosphorylation-dependent activation of STAT1 through IFNAR (de Almeida et al., 2011). In summary, our group has been dissecting host innate response pathways using $B$. abortus as a model of infection. The induction of type I IFN by this bacterium opens up a new avenue to study intracellular pathways induced by pathogens as a way to evade from host immune system.

\section{FUTURE PERSPECTIVES}

The past decade has witnessed great advances in our understanding of molecular mechanisms underlying innate immune system activation. Structural analysis of several TLRs have elucidated the mechanisms of PAMP recognition by TLR homoor heterodimers, and many signaling molecules involved in the activation of NF-kB, AP-1, and IRF proteins have been identified and characterized in detail. Regarding B. abortus infection, the TLR9 has been suggested so far as the most important single TLR to activate the host immune system. The identification of host receptors that recognize pathogen-derived nucleic acids has revealed an essential role for nucleic acid sensing in the triggering of immunity to intracellular pathogens. Our research group is currently identifying Brucella DNA motifs involved in activation of the host innate immune system. Nucleic acids act as adjuvants to activate innate immune programs via TLRs and/or other PRRs and have key roles in facilitating adaptive immunity to intracellular pathogens. Therefore, the use of PAMPs and/or endogenous agonists that stimulate immune cells will be critical for design new effective vaccines. Moreover, during a mammalian infection, B. abortus must establish a replicative niche in the presence of a robust innate immune system. The inflammasome is of critical importance to mount an effective innate immune response against intracellular pathogens. Investigation into the interaction of $B$. abortus and the inflammasomes might place a new perspective of sensing bacterial components. A better understanding of the mechanisms underlying Brucella interaction with inflammasomes may reveal important findings regarding IL-1 $\beta$ production and its association with the clinical symptoms of intermittent undulant fever, a hallmark of human patients with brucellosis. 
Understanding the complexity of the transcriptional networks that operate during innate immune receptors activation and define the subsequent immune responses and pathological manifestations during $B$. abortus infection is the major focus of our research.

\section{REFERENCES}

Abbott, D. W., Wilkins, A., Asara, J. M., and Cantley, L. C. (2004). The Crohn's disease protein, NOD2, requires RIP2 in order to induce ubiquitinylation of a novel site on NEMO. Curr. Biol. 14, 2217-2227.

Allen, I. C., Scull, M. A., Moore, C. B., Holl, E. K., McElvania-Tekippe, E., Taxman, D. J., et al. (2009). The NLRP3 inflammasome mediates in vivo innate immunity to influenza A virus through recognition of viral RNA. Immunity 30, 556-565.

Araj, G. F. (2010). Update on laboratory diagnosis of human brucellosis. Int. J. Antimicrob. Agents 36(Suppl. 1), S12-S17.

Arlehamn, C. S., and Evans, T. J. (2011). Pseudomonas aeruginosa pilin activates the inflammasome. Cell. Microbiol. 13, 388-401.

Auerbuch, V., Brockstedt, D. G., MeyerMorse, N., O'Riordan, M., and Portnoy, D. A. (2004). Mice lacking the type I interferon receptor are resistant to Listeria monocytogenes. J. Exp. Med. 200, 527-533.

Barber, G. N. (2011). Innate immune DNA sensing pathways: STING, AIMII and the regulation of interferon production and inflammatory responses. Curr. Opin. Immunol. 23, $10-20$

Bhoj, V. G., and Chen, Z. J. (2009). Ubiquitylation in innate and adaptive immunity. Nature 458, 430-437.

Blasius, A. L., and Beutler, B. (2010). Intracellular toll-like receptors. Immunity 32, 305-315.

Bonizzi, G., and Karin, M. (2004). The two NF-kappaB activation pathways and their role in innate and adaptive immunity. Trends Immunol. 25, 280-288.

Boyden, E. D., and Dietrich, W. F. (2006). Nalplb controls mouse macrophage susceptibility to anthrax lethal toxin. Nat. Genet. 38, 240-244.

Brandão, A. P., Oliveira, F. S., Carvalho, N. B., Vieira, L. Q., Azevedo, V., Macedo, G. C., et al. (2012). Host susceptibility to Brucella abortus infection is more pronounced in IFN-gamma knockout than IL-12/beta2-microglobulin doubledeficient mice. Clin. Dev. Immunol. 2012, 589494 .
Brierley, M. M., and Fish, E. N. (2002). Review: IFN-alpha/beta receptor interactions to biologic outcomes: understanding the circuitry. J. Interferon Cytokine Res. 22, 835-845.

Buss, C., Opitz, B., Hocke, A. C., Lippmann, J., Van Laak, V., Hippenstiel, S., et al. (2010). Essential role of mitochondrial antiviral signaling, IFN regulatory factor (IRF)3, and IRF7 in Chlamydophila pneumoniaemediated IFN-beta response and control of bacterial replication in human endothelial cells. J. Immunol. 184, 3072-3078.

Cargnello, M., and Roux, P. P. (2011). Activation and function of the MAPKs and their substrates, the MAPK-activated protein kinases. Microbiol. Mol. Biol. Rev. 75, 50-83.

Carrero, J. A., Calderon, B., and Unanue, E. R. (2004). Type I interferon sensitizes lymphocytes to apoptosis and reduces resistance to Listeria infection. J. Exp. Med. 200, 535-540.

Carrero, J. A., Calderon, B., and Unanue, E. R. (2006). Lymphocytes are detrimental during the early innate immune response against Listeria monocytogenes. J. Exp. Med. 203, 933-940.

Celli, J., De Chastellier, C., Franchini, D. M., Pizarro-Cerda, J., Moreno, E., and Gorvel, J. P. (2003). Brucella evades macrophage killing via VirBdependent sustained interactions with the endoplasmic reticulum. J. Exp. Med. 198, 545-556.

Chamaillard, M., Hashimoto, M., Horie, Y., Masumoto, J., Qiu, S., Saab, L., et al. (2003). An essential role for NOD1 in host recognition of bacterial peptidoglycan containing diaminopimelic acid. Nat. Immunol. 4, 702-707.

Chaturvedi, A., and Pierce, S. K. (2009). How location governs tolllike receptor signaling. Traffic 10, 621-628.

Chen, F., Ding, X., Ding, Y., Xiang, Z., Li, X., Ghosh, D., et al. (2011). Proinflammatory caspase-2mediated macrophage cell death induced by a rough attenuated Brucella suis strain. Infect. Immun. 79, 2460-2469.

Chen, F., and He, Y. (2009). Caspase-2 mediated apoptotic and necrotic

\section{ACKNOWLEDGMENTS}

This work was supported by grants from CNPq, CNPq/ANPCyT (\# 490528/2008-2), CNPq/CONICET, FAPEMIG, CAPES/PNPD, FAPEMIG/CNPq (PRONEX), CNPq/REPENSA and INCTVacinas.

murine macrophage cell death induced by rough Brucella abortus. PLoS ONE 4:e6830. doi: 10.1371/journal.pone.0006830

Chiu, Y. H., Macmillan, J. B., and Chen, Z. J. (2009). RNA polymerase III detects cytosolic DNA and induces type I interferons through the RIG-I pathway. Cell 138, 576-591.

Choubey, D., Duan, X., Dickerson, E., Ponomareva, L., Panchanathan, R., Shen, H., et al. (2010). Interferoninducible p200-family proteins as novel sensors of cytoplasmic DNA: role in inflammation and autoimmunity. J. Interferon Cytokine Res. 30, 371-380.

de Almeida, L. A., Carvalho, N. B., Oliveira, F. S., Lacerda, T. L., Vasconcelos, A. C., Nogueira, L., et al. (2011). MyD88 and STING signaling pathways are required for IRF3-mediated IFN-beta induction in response to Brucella abortus infection. PLoS ONE 6:e23135. doi: 10.1371/journal.pone.0023135

de Jong, M. F., and Tsolis, R. M. (2012). Brucellosis and type IV secretion. Future Microbiol. 7, 47-58.

de La Maza, L. M., Peterson, E. M., Goebel, J. M., Fennie, C. W., and Czarniecki, C. W. (1985). Interferon-induced inhibition of Chlamydia trachomatis: dissociation from antiviral and antiproliferative effects. Infect. Immun. 47, 719-722.

Decker, T., Muller, M., and Stockinger, S. (2005). The yin and yang of type I interferon activity in bacterial infection. Nat. Rev. Immunol. 5, 675-687.

Delpino, M. V., Barrionuevo, P., Macedo, G. C., Oliveira, S. C., Genaro, S. D., Scian, R., et al. (2012). Macrophage-elicited osteoclastogenesis in response to Brucella abortus infection requires TLR2/MyD88-dependent TNFalpha production. J. Leukoc. Biol. 91, 285-298.

Dranoff, G. (2004). Cytokines in cancer pathogenesis and cancer therapy. Nat. Rev. Cancer 4, 11-22.

Eigenbrod, T., Franchi, L., MunozPlanillo, R., Kirschning, C. J., Freudenberg, M. A., Nunez, G., et al. (2012). Bacterial RNA mediates activation of caspase- 1 and IL-1beta release independently of TLRs 3 7, 9 and TRIF but Is dependent on UNC93B. J. Immunol. 189, 328-336.
Elinav, E., Strowig, T., Henao-Mejia, J., and Flavell, R. A. (2011). Regulation of the antimicrobial response by NLR proteins. Immunity 34, 665-679.

Faustin, B., Lartigue, L., Bruey, J. M., Luciano, F., Sergienko, E., Bailly-Maitre, B., et al. (2007). Reconstituted NALP1 inflammasome reveals two-step mechanism of caspase-1 activation. Mol. Cell 25, 713-724.

Fehr, T., Schoedon, G., Odermatt, B., Holtschke, T., Schneemann, M., Bachmann, M. F., et al. (1997). Crucial role of interferon consensus sequence binding protein, but neither of interferon regulatory factor 1 nor of nitric oxide synthesis for protection against murine listeriosis. J. Exp. Med. 185, 921-931.

Fernandes-Alnemri, T., Wu, J., Yu, J. W., Datta, P., Miller, B., Jankowski, W., et al. (2007). The pyroptosome: a supramolecular assembly of ASC dimers mediating inflammatory cell death via caspase-1 activation. Cell Death Differ. 14, 1590-1604.

Fernandes-Alnemri, T., Yu, J. W., Juliana, C., Solorzano, L., Kang, S., Wu, J., et al. (2010). The AIM2 inflammasome is critical for innate immunity to Francisella tularensis. Nat. Immunol. 11, 385-393.

Fraczek, J., Kim, T. W., Xiao, H., Yao, J., Wen, Q., Li, Y., et al. (2008). The kinase activity of IL-1 receptorassociated kinase 4 is required for interleukin-1 receptor/toll-like receptor-induced TAK1-dependent NFkappaB activation. J. Biol. Chem. 283, 31697-31705.

Franchi, L., Eigenbrod, T., MunozPlanillo, R., and Nunez, G. (2009a). The inflammasome: a caspase-1activation platform that regulates immune responses and disease pathogenesis. Nat. Immunol. 10, 241-247.

Franchi, L., Warner, N., Viani, K. and Nunez, G. (2009b). Function of Nod-like receptors in microbial recognition and host defense. Immunol. Rev. 227, 106-128.

Franchi, L., Munoz-Planillo, R., and Nunez, G. (2012). Sensing and reacting to microbes through the inflammasomes. Nat. Immunol. 13, 325-332.

Freudenberg, M. A., Merlin, T., Kalis, C., Chvatchko, Y., Stubig, H., and 
Galanos, C. (2002). Cutting edge: a murine, IL-12-independent pathway of IFN-gamma induction by gram-negative bacteria based on STAT4 activation by Type I IFN and IL-18 signaling. J. Immunol. 169, 1665-1668.

Frutuoso, M. S., Hori, J. I., Pereira, M. S., Junior, D. S., Sonego, F., Kobayashi, K. S., et al. (2010). The pattern recognition receptors Nod1 and Nod2 account for neutrophil recruitment to the lungs of mice infected with Legionella pneumophila. Microbes Infect. 12, 819-827.

Gandotra, S., Jang, S., Murray, P. J., Salgame, P., and Ehrt, S. (2007). Nucleotide-binding oligomerization domain protein 2-deficient mice control infection with Mycobacterium tuberculosis. Infect. Immun. 75, 5127-5134.

Giambartolomei, G. H., Zwerdling, A., Cassataro, J., Bruno, L., Fossati, C. A., and Philipp, M. T. (2004). Lipoproteins, not lipopolysaccharide, are the key mediators of the proinflammatory response elicited by heat-killed Brucella abortus. J. Immunol. 173, 4635-4642.

Glomski, I. J., Fritz, J. H., Keppler, S. J., Balloy, V., Chignard, M., Mock, M., et al. (2007). Murine splenocytes produce inflammatory cytokines in a MyD88-dependent response to Bacillus anthracis spores. Cell. Microbiol. 9, 502-513.

Godfroid, J., Scholz, H. C., Barbier, T., Nicolas, C., Wattiau, P., Fretin, D., et al. (2011). Brucellosis at the ani$\mathrm{mal} /$ ecosystem/human interface at the beginning of the 21st century. Prev. Vet. Med. 102, 118-131.

Gold, J. A., Hoshino, Y., Hoshino, S., Jones, M. B., Nolan, A., and Weiden, M. D. (2004). Exogenous gamma and alpha/beta interferon rescues human macrophages from cell death induced by Bacillus anthracis. Infect. Immun. 72, 1291-1297.

Gratz, N., Siller, M., Schaljo, B., Pirzada, Z. A., Gattermeier, I., Vojtek, I., et al. (2008). Group A streptococcus activates type I interferon production and MyD88-dependent signaling without involvement of TLR2, TLR4, and TLR9. J. Biol. Chem. 283, 19879-19887.

Halle, A., Hornung, V., Petzold, G. C., Stewart, C. R., Monks, B. G., Reinheckel, T., et al. (2008). The NALP3 inflammasome is involved in the innate immune response to amyloid-beta. Nat. Immunol. 9, 857-865.

Haque, A., Best, S. E., Ammerdorffer, A., Desbarrieres, L., De Oca, M. M.
Amante, F. H., et al. (2011). Type I interferons suppress CD4(+) T-celldependent parasite control during blood-stage Plasmodium infection. Eur. J. Immunol. 41, 2688-2698.

Hashimoto, C., Hudson, K. L., and Anderson, K. V. (1988). The Toll gene of Drosophila, required for dorsal-ventral embryonic polarity, appears to encode a transmembrane protein. Cell 52, 269-279.

Henry, T., Kirimanjeswara, G. S., Ruby, T., Jones, J. W., Peng, K., Perret, M., et al. (2010). Type I IFN signaling constrains IL-17A/F secretion by gammadelta $\mathrm{T}$ cells during bacterial infections. J. Immunol. 184, 3755-3767.

Honda, K., and Taniguchi, T. (2006). IRFs: master regulators of signalling by Toll-like receptors and cytosolic pattern-recognition receptors. Nat. Rev. Immunol. 6, 644-658.

Hornung, V., Ablasser, A., CharrelDennis, M., Bauernfeind, F., Horvath, G., Caffrey, D. R., et al. (2009). AIM2 recognizes cytosolic dsDNA and forms a caspase-1activating inflammasome with ASC. Nature 458, 514-518.

Hornung, V., Bauernfeind, F., Halle, A., Samstad, E. O., Kono, H., Rock, K. L., et al. (2008). Silica crystals and aluminum salts activate the NALP3 inflammasome through phagosomal destabilization. Nat. Immunol. 9, 847-856.

Hruz, P., Zinkernagel, A. S., Jenikova, G., Botwin, G. J., Hugot, J. P., Karin, M., et al. (2009). NOD2 contributes to cutaneous defense against Staphylococcus aureus through alpha-toxin-dependent innate immune activation. Proc. Natl. Acad. Sci. U.S.A. 106, 12873-12878.

Huang, L. Y., Ishii, K. J., Akira, S., Aliberti, J., and Golding, B. (2005). Th1-like cytokine induction by heat-killed Brucella abortus is dependent on triggering of TLR9. J. Immunol. 175, 3964-3970.

Isaacs, A., and Lindenmann, J. (1957). Virus interference. I. The interferon. Proc. R. Soc. Lond. B Biol. Sci. 147, 258-267.

Ishihara, T., Aga, M., Hino, K., Ushio, C., Taniguchi, M., Iwaki, K., et al. (2005). Inhibition of Chlamydia trachomatis growth by human interferon-alpha: mechanisms and synergistic effect with interferon-gamma and tumor necrosis factor-alpha. Biomed. Res. 26, 179-185.

Ishikawa, H., and Barber, G. N. (2008). STING is an endoplasmic reticulum adaptor that facilitates innate immune signalling. Nature 455, 674-678.
Jiménez De Bagüés, M. P., Gross, A., Terraza, A., and Dornand, J. (2005). Regulation of the mitogenactivated protein kinases by Brucella spp. expressing a smooth and rough phenotype: relationship to pathogen invasiveness. Infect. Immun. 73, 3178-3183.

Kang, J. Y., Nan, X., Jin, M. S. Youn, S. J., Ryu, Y. H., Mah, S., et al. (2009). Recognition of lipopeptide patterns by Tolllike receptor 2-Toll-like receptor 6 heterodimer. Immunity 31 , 873-884.

Kanneganti, T. D., Ozoren, N., BodyMalapel, M., Amer, A., Park, J. H., Franchi, L., et al. (2006). Bacterial RNA and small antiviral compounds activate caspase-1 through cryopyrin/Nalp3. Nature 440, 233-236.

Kawai, T., and Akira, S. (2011). Tolllike receptors and their crosstalk with other innate receptors in infection and immunity. Immunity 34, 637-650.

Keestra, A. M., Winter, M. G., KleinDouwel, D., Xavier, M. N., Winter, S. E., Kim, A., et al. (2011). A Salmonella virulence factor activates the NOD1/NOD2 signaling pathway. MBio 2, 266-276.

Kenny, E. F., and O'Neill, L. A. (2008). Signalling adaptors used by Toll-like receptors: an update. Cytokine 43, 342-349.

Kim, Y. M., Brinkmann, M. M., Paquet, M. E., and Ploegh, H. L. (2008). UNC93B1 delivers nucleotide-sensing toll-like receptors to endolysosomes. Nature 452, 234-238.

Kobayashi, K., Inohara, N., Hernandez, L. D., Galan, J. E., Nunez, G., Janeway, C. A., et al. (2002). RICK/Rip2/CARDIAK mediates signalling for receptors of the innate and adaptive immune systems. Nature 416, 194-199.

Kobayashi, K. S., Chamaillard, M. Ogura, Y., Henegariu, O., Inohara, N., Nuñez, G., et al. (2005). Nod2-dependent regulation of innate and adaptive immunity in the intestinal tract. Science 307, 731-734.

Kondo, T., Kawai, T., and Akira, S. (2012). Dissecting negative regulation of Toll-like receptor signaling. Trends Immunol. 33, 449-458.

Kumar, H., Kawai, T., and Akira, S. (2011). Pathogen recognition by the innate immune system. Int. Rev. Immunol. 30, 16-34.

Lamkanfi, M., and Dixit, V. M. (2009). The inflammasomes. PLoS Pathog. 5:e1000510. doi: 10.1371/journal.ppat.1000510
Li, X., and He, Y. (2012). Caspase-2dependent dendritic cell death, maturation, and priming of $\mathrm{T}$ cells in response to Brucella abortus infection. PLoS ONE 7:e43512. doi: 10.1371/journal.pone.0043512

Macedo, G. C., Magnani, D. M., Carvalho, N. B., Bruna-Romero, O., Gazzinelli, R. T., and Oliveira, S. C. (2008). Central role of MyD88dependent dendritic cell maturation and proinflammatory cytokine production to control Brucella abortus infection. J. Immunol. 180, 1080-1087.

Manca, C., Tsenova, L., Freeman, S., Barczak, A. K., Tovey, M., Murray, P. J., et al. (2005). Hypervirulent, M. tuberculosis W/Beijing strains upregulate type I IFNs and increase expression of negative regulators of the Jak-Stat pathway. J. Interferon Cytokine Res. 25, 694-701.

Mancuso, G., Gambuzza, M., Midiri, A., Biondo, C., Papasergi, S., Akira S., et al. (2009). Bacterial recognition by TLR7 in the lysosomes of conventional dendritic cells. Nat. Immunol. 10, 587-594.

Mariathasan, S., Newton, K., Monack, D. M., Vucic, D., French, D. M. Lee, W. P., et al. (2004). Differential activation of the inflammasome by caspase-1 adaptors ASC and Ipaf. Nature 430, 213-218.

Mariathasan, S., Weiss, D. S., Newton, K., McBride, J., O'Rourke, K., Roose-Girma, M., Lee, W. P., et al. (2006). Cryopyrin activates the inflammasome in response to toxins and ATP. Nature 440, 228-232.

Martinon, F., Mayor, A., and Tschopp, J. (2009). The inflammasomes: guardians of the body. Annu. Rev. Immunol. 27, 229-265.

Massis, L. M., and Zamboni, D. S. (2011). Innate immunity to Legionella pneumophila. Front. Microbiol. 2:109. doi: 10.3389/fmicb.2011.00109

Meissner, N. N., Swain, S., Tighe, M., Harmsen, A., and Harmsen, A. (2005). Role of type I IFNs in pulmonary complications of Pneumocystis murina infection. J. Immunol. 174, 5462-5471.

Miao, E. A., Mao, D. P., Yudkovsky, N., Bonneau, R., Lorang, C. G., Warren, S. E., et al. (2010). Innate immune detection of the type III secretion apparatus through the NLRC4 inflammasome. Proc. Natl. Acad. Sci. U.S.A. 107, 3076-3080.

Miao, E. A., Rajan, J. V., and Aderem, A. (2011). Caspase-1-induced pyroptotic cell death. Immunol. Rev. 243, 206-214.

Monroe, K. M., McWhirter, S. M., and Vance, R. E. (2010). Induction of 
type I interferons by bacteria. Cell. Microbiol. 12, 881-890.

Nagarajan, U. M., Sikes, J., Prantner, D., Andrews, C. W. Jr., Frazer, L., Goodwin, A., et al. (2011). MyD88 deficiency leads to decreased NK cell gamma interferon production and $\mathrm{T}$ cell recruitment during Chlamydia muridarum genital tract infection, but a predominant Th1 response and enhanced monocytic inflammation are associated with infection resolution. Infect. Immun. 79, 486-498.

O'Connell, R. M., Saha, S. K., Vaidya, S. A., Bruhn, K. W., Miranda, G. A., Zarnegar, B., et al. (2004). Type I interferon production enhances susceptibility to Listeria monocytogenes infection. J. Exp. Med. 200, 437-445.

O'Connor, W. Jr., Kamanaka, M., Booth, C. J., Town, T., Nakae, S., Iwakura, Y., et al. (2009). A protective function for interleukin $17 \mathrm{~A}$ in $\mathrm{T}$ cell-mediated intestinal inflammation. Nat. Immunol. 10, 603-609.

Oliveira, F. S., Carvalho, N. B., Brandao, A. P., Gomes, M. T., De Almeida, L. A., and Oliveira, S. C. (2011). Interleukin-1 receptor-associated kinase 4 is essential for initial host control of Brucella abortus infection. Infect. Immun. 79, 4688-4695.

Oliveira, F. S., Carvalho, N. B., Zamboni, D. S., and Oliveira, S. C. (2012). Nucleotide-binding oligomerization domain-1 and -2 play no role in controlling Brucella abortus infection in mice. Clin. Dev. Immunol. 2012, 861426.

Pappas, G. (2010). The changing Brucella ecology: novel reservoirs, new threats. Int. J. Antimicrob. Agents 36(Suppl. 1), S8-S11.

Parent, M. A., Goenka, R., Murphy, E., Levier, K., Carreiro, N., Golding, B., et al. (2007). Brucella abortus bacA mutant induces greater proinflammatory cytokines than the wild-type parent strain. Microbes Infect. 9, 55-62.

Park, B. S., Song, D. H., Kim, H. M., Choi, B. S., Lee, H., and Lee, J. O. (2009). The structural basis of lipopolysaccharide recognition by the TLR4-MD-2 complex. Nature 458, 1191-1195.

Pasquevich, K. A., Garcia Samartino, C., Coria, L. M., Estein, S. M., Zwerdling, A., Ibanez, A. E., et al. (2010). The protein moiety of Brucella abortus outer membrane protein 16 is a new bacterial pathogen-associated molecular pattern that activates dendritic cells in vivo, induces a Th1 immune response, and is a promising self-adjuvanting vaccine against systemic and oral acquired brucellosis. J. Immunol. 184, 5200-5212.

Pauleau, A. L., and Murray, P. J. (2003). Role of nod2 in the response of macrophages to toll-like receptor agonists. Mol. Cell. Biol. 23, 7531-7539.

Petrilli, V., Papin, S., Dostert, C., Mayor, A., Martinon, F., and Tschopp, J. (2007). Activation of the NALP3 inflammasome is triggered by low intracellular potassium concentration. Cell Death Differ. 14, 1583-1589.

Plumlee, C. R., Lee, C., Beg, A. A., Decker, T., Shuman, H. A., and Schindler, C. (2009). Interferons direct an effective innate response to Legionella pneumophila infection. J. Biol. Chem. 284, 30058-30066.

Prantner, D., Darville, T., and Nagarajan, U. M. (2010). Stimulator of IFN gene is critical for induction of IFN-beta during Chlamydia muridarum infection. J. Immunol. 184, 2551-2560.

Qiu, H., Fan, Y., Joyee, A. G., Wang, S., Han, X., Bai, H., et al. (2008). Type I IFNs enhance susceptibility to Chlamydia muridarum lung infection by enhancing apoptosis of local macrophages. J. Immunol. 181, 2092-2102.

Rathinam, V. A., Jiang, Z., Waggoner, S. N., Sharma, S., Cole, L. E., Waggoner, L., et al. (2010). The AIM2 inflammasome is essential for host defense against cytosolic bacteria and DNA viruses. Nat. Immunol. $11,395-402$.

Salcedo, S. P., Marchesini, M. I., Lelouard, H., Fugier, E., Jolly, G., Balor, S., et al. (2008). Brucella control of dendritic cell maturation is dependent on the TIR-containing protein Btp1. PLoS Pathog. 4:e21. doi: 10.1371/journal.ppat.0040021

Sato, S., Sugiyama, M., Yamamoto, M., Watanabe, Y., Kawai, T., Takeda, K., et al. (2003). Toll/IL-1 receptor domain-containing adaptor inducing IFN-beta (TRIF) associates with TNF receptor-associated factor 6 and TANK-binding kinase 1 , and activates two distinct transcription factors, NF-kappa B and IFNregulatory factor-3, in the Toll-like receptor signaling. J. Immunol. 171, 4304-4310.
Schroder, K., and Tschopp, J. (2010). The inflammasomes. Cell 140, 821-832.

Sharma, S., Deoliveira, R. B., Kalantari, P., Parroche, P., Goutagny, N., Jiang, Z., et al. (2011). Innate immune recognition of an AT-rich stemloop DNA motif in the Plasmodium falciparum genome. Immunity 35, 194-207.

Shaw, M. H., Reimer, T., Kim, Y. G., and Nunez, G. (2008). NOD-like receptors (NLRs): bona fide intracellular microbial sensors. Curr. Opin. Immunol. 20, 377-382.

Sorrentino, A., Thakur, N., Grimsby, S., Marcusson, A., Von Bulow, V., Schuster, N., et al. (2008). The type I TGF-beta receptor engages TRAF6 to activate TAK1 in a receptor kinase-independent manner. Nat. Cell Biol. 10, 1199-1207.

Stockinger, S., and Decker, T. (2008). Novel functions of type I interferons revealed by infection studies with Listeria monocytogenes. Immunobiology 213, 889-897.

Takaoka, A., Wang, Z., Choi, M. K., Yanai, H., Negishi, H., Ban, T., et al. (2007). DAI (DLM-1/ZBP1) is a cytosolic DNA sensor and an activator of innate immune response. Nature 448, 501-505.

Trinchieri, G. (2010). Type I interferon: friend or foe? J. Exp. Med. 207, 2053-2063.

Viala, J., Chaput, C., Boneca, I. G., Cardona, A., Girardin, S. E., Moran, A. P., et al. (2004). Nod1 responds to peptidoglycan delivered by the Helicobacter pylori cag pathogenicity island. Nat. Immunol. 5, 1166-1174.

Vivarini Ade, C., Pereira Rde, M., Teixeira, K. L., Calegari-Silva, T. C., Bellio, M., Laurenti, M. D., et al. (2011). Human cutaneous leishmaniasis: interferon-dependent expression of double-stranded RNA-dependent protein kinase (PKR) via TLR2. FASEB J. 25, 4162-4173.

Weiss, D. S., Takeda, K., Akira, S., Zychlinsky, A., and Moreno, E. (2005). MyD88, but not toll-like receptors 4 and 2, is required for efficient clearance of Brucella abortus. Infect. Immun. 73, 5137-5143.

Yamasaki, K., Muto, J., Taylor, K. R., Cogen, A. L., Audish, D., Bertin, J., et al. (2009). NLRP3/cryopyrin is necessary for interleukin-lbeta (IL-1beta) release in response to hyaluronan, an endogenous trigger of inflammation in response to injury. J. Biol. Chem. 284, 12762-12771.

Yang, P., An, H., Liu, X., Wen, M., Zheng, Y., Rui, Y., et al. (2010). The cytosolic nucleic acid sensor LRRFIP1 mediates the production of type I interferon via a betacatenin-dependent pathway. Nat. Immunol. 11, 487-494.

Yoneyama, M., Kikuchi, M., Matsumoto, K., Imaizumi, T., Miyagishi, M., Taira, K., et al. (2005). Shared and unique functions of the DExD/H-box helicases RIG-I, MDA5, and LGP2 in antiviral innate immunity. J. Immunol. 175, 2851-2858.

Yoon, S. I., Kurnasov, O., Natarajan, V., Hong, M., Gudkov, A. V., Osterman, A. L., et al. (2012). Structural basis of TLR5-flagellin recognition and signaling. Science 335, 859-864.

Zhang, C. Y., Bai, N., Zhang, Z. H., Liang, N., Dong, L., Xiang, R., et al. (2012). TLR2 signaling subpathways regulate TLR9 signaling for the effective induction of IL-12 upon stimulation by heat-killed Brucella abortus. Cell. Mol. Immunol. 9, 324-333.

Zhu, J., and Mohan, C. (2010). Toll-like receptor signaling pathways-therapeutic opportunities. Mediators Inflamm. 2010, 781235.

Conflict of Interest Statement: The authors declare that the research was conducted in the absence of any commercial or financial relationships that could be construed as a potential conflict of interest.

Received: 29 July 2012; accepted: 04 October 2012; published online: 25 October 2012.

Citation: Gomes MTR, Campos PC, de Almeida LA, Oliveira FS, Costa MMS, Marim FM, Pereira GSM and Oliveira SC (2012) The role of innate immune signals in immunity to Brucella abortus. Front. Cell. Inf. Microbio. 2:130. doi: 10.3389/fcimb.2012.00130

Copyright (ㄷ) 2012 Gomes, Campos, de Almeida, Oliveira, Costa, Marim, Pereira and Oliveira. This is an openaccess article distributed under the terms of the Creative Commons Attribution License, which permits use, distribution and reproduction in other forums, provided the original authors and source are credited and subject to any copyright notices concerning any third-party graphics etc. 